\title{
Mona Lisa: sentidos múltiplos de um sorriso enigmático
} Mona Lisa: multiple meanings of an enigmatic smile

Érika de Moraes (Faac, Unesp Bauru/FEsTA)

\section{RESUMO}

Este texto resgata um pouco da história da famosa pintura de Leonardo da Vinci, a Mona Lisa, ou Gioconda, do século XVI, com objetivo de discorrer a respeito de alguns dos múltiplos sentidos (ou discursos) em torno de seu significado, tendo como suporte o respaldo teórico-metodológico da Análise do Discurso de linha francesa, com base especialmente em conceitos desenvolvidos por D. Maingueneau. Como é característico da obra de arte, trata-se de efeitos de sentidos em aberto, o que não exclui a possibilidade de destacamentos, entre os quais se sobressai o "sorriso de Mona Lisa" como um dos principais traços da autoria de Leonardo Da Vinci e, simultaneamente, um traço propício à aforização. Assim, a obra de arte desvincula-se da autoria exclusiva de Da Vinci ao suscitar diversas releituras, as quais ajudam a compor um ethos discursivo em torno desta consagrada pintura e, ao mesmo tempo, fazem circular estereótipos distintos.

Palavras-chave: Mona Lisa; ethos discursivo; aforização; autoria. 


\section{ABSTRACT}

This article reviews the history of the famous painting by Leonardo da Vinci, the Mona Lisa or Gioconda, sixteenth century, aiming to discuss about some of the multiple senses (or discourses) around its meaning, with the support of the French branch of the Discourse Analysis, especially based on concepts developed by D. Maingueneau. As it is characteristic of the work of art, the senses are open, which does not exclude the possibility of detachment, among which we accentuated the "Mona Lisa smile" as one of the main traits of the authorship by Leonardo Da Vinci and, simultaneously, a trait propitious to aphorisation. Thus, the work of art is releasing of the exclusive authorship of Da Vinci and it suscitates several rereadings, which help composing a discursive ethos around this consecrated painting and, at the same time, which make circulating distinct stereotypes.

Key-words: Mona Lisa; discursive ethos; aphorisation; autorship

\section{Da criação à eternização no Louvre - um breve retorno}

Do you smile to tempt a lover, Mona Lisa? Or is this your way to hide a broken heart?

Are you warm, are you real, Mona Lisa? Or just a cold and lonely, lovely work of art? (Mona Lisa, Nat King Cole)

Figura 1: Mona Lisa. (Retrato de Mona Lisa, La Gioconda, Leonardo Da Vinci. Fonte: www.dominiopublico.gov.br) 
A Mona Lisa, ou Gioconda, encontra-se hoje no Musée du Louvre, em Paris, protegida por um vidro e também por seguranças. O quadro mede 77 por 53 centímetros e, por questões de conservação, pode ser apreciado apenas através de um cordão que demarca o limite até onde o público pode se aproximar. É recomendável chegar cedo ao Louvre e começar a visita por ela, já que é a atração mais concorrida do maior museu do mundo. Talvez seja a obra de arte mais famosa de todas no mais suntuoso museu. Apesar das rachaduras de tinta e marcas de verniz ressecado, os cuidados atuais com a sua preservação, especialmente em relação à temperatura monitorada atrás do quadro, ajudam a conservá-lo em sua sala especial do Louvre, a Salle de la Joconde, onde reina rodeada por outras obras cuja grandeza só servem para enaltecê-la ainda mais.

Não foi sempre assim. Na época de sua criação, não se podia sequer imaginar a dimensão de excepcionalidade com que seria considerada, tampouco os seus mistérios, ainda que seu criador, Leonardo Da Vinci (1452-1519), tenha obtido credibilidade em seu tempo. Como afirma Henri Loyrette, presidente-diretor do Musée du Louvre, em prefácio ao livro La Joconde (2005), jamais a história desse quadro foi tão acessível como nos dias de hoje, quando o conhecimento histórico e científico sobre A Gioconda é complexo e diversificado. Mesmo assim, "estranhamente, jamais os fantasmas a respeito dessa obra e seus mistérios estiveram também tão presentes" (Loyrette 2005: 3). Assim, "como todas as obras de arte, A Gioconda conserva sua parte de hermetismo, de sonho, de poesia atemporal e de mensagem universal, que, por essência, suscita todas as interpretações" (Loyrette 2005: 3).

Tais "interpretações" podem ser entendidas como efeitos de sentido, conforme o dispositivo teórico-metodológico da Análise do Discurso de linha francesa, trazendo novas luzes a respeito da significação desta obra enquanto discurso, o que, de maneira alguma, invalida a sua importância enquanto obra de arte. Simultaneamente, a compreensão de efeitos de sentido em torno do famoso quadro permite uma reflexão sobre algumas noções, como a de ethos e de autoria, conforme será demonstrado no decorrer da discussão. Tendo em vista a importância das condições de produção para a teoria discursiva, propomos, primeiramente, um breve retorno histórico às origens desta obra. 
A Mona Lisa teria sido pintada em Florença, nos primeiros anos do século XVI (entre 1503 e 1506), ocasião em que Da Vinci vivia por lá. A hipótese mais provável sobre a sua criação, sustentada atualmente por especialistas, é que Leonardo teria aceitado realizar o retrato da esposa de um rico comerciante da vila, Francesco del Giocondo. A modelo, Lisa di Noldo Gherardini, teria nascido em 1479 e se casado em 1495 com Francesco del Giocondo, com quem teve três filhos.

No entanto, o que fascina nesse quadro é o fato de representar muito mais do que uma personagem real, sem deixar de sê-lo. Como comentam os especialistas, a pintura demonstra muito bem a posição social da personagem que, por trás da sobriedade, vê-se representada em detalhes, como, no caso das vestimentas, pelo largo decote com bordados dourados. Trata-se, então, por um lado, do retrato da jovem esposa de um rico comerciante. Por outro, "Leonardo, com toda evidência, ultrapassou os aspectos convencionais do retrato, desenvolvendo, através desta obra, toda uma analogia entre a natureza do ser humano, o macrocosmo e o microcosmo" (Douar 2005: 10). Sabe-se que há toda uma evocação de humanidade, para além da representação de uma pessoa, na imagem de Mona Lisa, especialmente em seu enigmático sorriso. Diz-se, ainda, que o quadro não deixa de compor um "autorretrato mental" (Loyrette 2005: 3).

Tecnicamente, embora a teoria que Da Vinci sistematizou ("um conjunto coerente de observações engenhosas e de anotações racionais", conforme Vaux 1943: 20) tenha se tornado clássica, sua releitura proporciona perceber "seu sabor bem moderno" (Vaux 1943: 20), caracterizado por aspectos que foram pouco aplicados na arte da chamada época clássica. Segundo Vaux, é bem complexo caracterizar o estilo de Da Vinci.

A verdade é que nos encontramos, com Leonardo, em presença de uma arte ao mesmo tempo muito profunda e muito refinada. (...) Ela não é, falando com maior propriedade, clássica [cujas formas são mais quadradas, mais nítidas, mais vigorosas; com delicadeza e sinuosidade]. Esta arte não é também gótica [cujas formas são mais agudas e o espírito mais rígido]. Esta arte de Da Vinci pode parecer moderna pelo gosto do rebuscamento e da raridade. (Vaux 1943: 32) 
Conforme aponta reportagem da revista Veja (2004), com esclarecimentos do historiador Peter Burke, o Renascimento é um período histórico constantemente reinterpretado. O período que o antecede não teria sido propriamente uma Idade de Trevas, mas uma fase caracterizada pela falta de comunicação entre diversos polos culturais. Assim, Da Vinci teria sido o "herdeiro e organizador de séculos de avanços desconexos" (Teixeira, 2004: 94). Segundo Burke, entrevistado pela reportagem, "o passado exercia grande autoridade sobre os artistas do Renascimento, o que impede que sejam vistos como 'revolucionários' no modelo dos vanguardistas do século XX” (apud Teixeira 2004: 96).

Há, na obra de Da Vinci, aspectos avançados para a época, os quais coexistem com "traços de ingenuidade e de secura, [que] nos levam para o passado, para uma época primitiva" (Vaux 1943: 33). Ainda segundo Vaux (1943: 35-36), “o modo pelo qual Leonardo concebeu a beleza geral de seus quadros, o ar e a luz, é muito pessoal também, e em harmonia com sua concepção do belo nas figuras. A calma e a serenidade reinam no conjunto; o pitoresco e o bizarro se encontram nos detalhes".

Sobre seu mais célebre quadro, A Mona Lisa, diz-se que é o principal enigma da obra de Da Vinci. Sua intensidade consiste, sobretudo, no fato de que "a expressão sobrepassa enormemente a possível psicologia do modelo, por mais amável e inteligente que tenha sido a dama florentina, nem para que seu sorriso, ao mesmo tempo sedutor e reservado, pareça conter sugestões tão misteriosas" (Vaux 1943: 45). Assim, o autor conclui: "Sob o pretexto de pintar sua compatriota, Leonardo da Vinci, quer tenha ou não buscado, exprimiu, certamente, uma outra coisa; alguma concepção que estava nele, tinha-se, à maneira de um espírito, introduzido nesta figura de mulher e serviu para representá-la" (Vaux 1943: 45).

Vê-se, portanto, que a fisionomia e a expressão são aspectos considerados dos mais relevantes por Da Vinci. Conforme anota Vaux (1943: 26-27), Da Vinci "recomenda escolher sempre para as figuras que se quer desenhar o movimento mais natural, aquele que nasce espontaneamente sob o efeito de cada impressão". Considera ainda que "a expressão e o caráter dos rostos interessava nosso artista quase no mesmo grau que a beleza" (Vaux 1943: 34). 
A técnica batizada por Leonardo como sfumato contribuía para aumentar a expressividade de suas representações. Consistia em usar sucessivas camadas de cor, com variações mínimas de tom, eliminando linhas de contorno, para dar maior naturalidade à iluminação natural e, ao mesmo tempo, conferir maior volume e profundidade.

Sabe-se, ainda, que a paisagem, "uma arte que só adquiriu independência na época contemporânea" (Vaux 1943: 20), foi considerada por Da Vinci como uma importante parte da pintura.

Douar reforça que a água é um dos objetos privilegiados das pesquisas de Leonardo e ele a avoca neste quadro de duas maneiras diferentes: viva, à direita, em um rio que desenha; e calma, à esquerda e em todo fundo à direita no lago que forma. Ela "representa simbolicamente a passagem, a transição entre dois estados interiores" (Douar 2005: 10). Assim, segundo o autor, isso parece redobrar o efeito do sorriso de Mona Lisa, denotando "um movimento interior, a animação do ânimo de Gioconda, cujo nome italiano deriva do adjetivo latino jucundus que significa serena, agradável" (Douar 2005: 10).

Também as cores empregadas por Da Vinci revelam uma observação criteriosa da natureza:

Leonardo aconselha olhar o arco-íris; obter-se-á um efeito agradável colocando uma após outra as que são vizinhas no arco-íris, como o verde e o azul, ou que são, ao contrário, completamente opostas, tais como o vermelho e o verde. Para Leonardo o branco não é uma cor em si, mas um 'receptáculo' de todas as cores. Não sei se os historiadores da ciência observaram suficientemente estas ideias muito sugestivas sobre o espectro, na qual pôde se inspirar Newton. (Vaux 1943: 23-24)

Vaux sinaliza ainda a importância das cores secundárias que os objetos recebem dos outros que os circundam, os reflexos. Por sua observação cuidadosa da natureza e de suas cores, Da Vinci teria se aproximado do impressionismo: "Eu muitas vezes vi, observa Leonardo, em um objeto branco, as luzes róseas, e as sombras azuladas; isso acontece nas montanhas cobertas de neve, quando o sol está no ocaso e parece um braseiro" (Vaux 1943: 25). Ainda é importante considerar que $\mathrm{Da}$ Vinci dispendia um bom tempo na elaboração de seus quadros. 
Em sua arte, conjugava o conhecimento que buscava em todas as áreas: a geometria, a dinâmica, a anatomia, a fisiologia.

A dimensão da fama da pintura de Leonardo Da Vinci, sem excluir suas qualidades artísticas, também se deve a uma conjuntura. Como defende o historiador Donald Sassoon (2004), é significativo o fato de que o autor tenha levado consigo o quadro a Paris, quando, em 1516, foi para a corte do rei Francisco I. Foi dessa forma que a obra se integrou ao centro europeu mais intensamente dedicado à arte, sendo, após a revolução francesa, incorporada ao acervo do Louvre. Após isso, passou um tempo nos aposentos de Napoleão Bonaparte e, posteriormente, foi resgatada pelo Louvre. No século XIX, a mitificação em torno da Mona Lisa intensificou-se. Sua fama se popularizou após o roubo do Louvre, em 1911, e posterior recuperação, em 1913, quando se tornou manchete dos principais jornais e, só então, passou à condição de ícone global. Sofreu, ainda, posteriormente, um atentado, o que justifica o esquema de segurança em torno dela.

Aponta a revista Veja que, tamanha a sua vulgarização, a Mona Lisa esteve perto de ser convertida em uma imagem kitsch, "a obraprima preferida de quem não conhece nenhuma outra obra-prima" (Teixeira 2004: 100). Totalmente popularizada, tornou-se objeto de consumo, ilustrando os mais diversos itens da cultura popular (camisetas, chocolates, ímãs de geladeira etc.), citada em letras de músicas, sem deixar de ser reconhecida como uma das maiores obras de arte da cultura ocidental, a única a ocupar uma sala própria, especialmente desenvolvida para ela, no Musée du Louvre. Conforme defende Donald Sassoon (2004), ela pertence ao mesmo tempo aos cânones da chamada alta cultura e da cultura pop. Tanto é parte da história da arte no sentido mais tradicional quanto é objeto de consumo e da cultura popular massificada, fonte das mais diversas retomadas.

Este breve histórico não tem a intenção de ser completo no que tange aos aspectos artísticos da criação de Leonardo Da Vinci, apenas o de resumir um pouco do que há de consenso a respeito de suas condições de produção e das principais características da obra. O propósito é situar esse terreno fértil a fim de propor uma abordagem discursiva, com objetivo de discorrer a respeito de alguns dos múltiplos sentidos (ou discursos) em torno de seu significado. Como é característico da 
obra de arte, os efeitos de sentido são vários, porém, em seu conjunto, configuram um ethos discursivo em torno desta consagrada pintura, conforme procuraremos explicitar durante o trabalho. Por questões de delimitação, trataremos mais de aspectos referentes à expressão do que a outros como a paisagem e o uso de cores.

\section{Subsídios teórico-metodológicos para uma reflexão sobre Mona Lisa}

Para a Análise do Discurso de linha francesa (doravante, AD), o sentido deve ser entendido como um construto a partir dos discursos correntes, relacionado a posicionamentos ideológicos e às condições históricas de produção. Como ressalta Maingueneau (1997), com base nos estudos de Pêcheux, não se trata de buscar "o" sentido por excelência, mas evidenciar interpretações que não se neutralizam e ressaltem estratégias de sujeitos (históricos) nos níveis opacos da linguagem.

Do ponto de vista da AD, considerando-se especialmente formulações recentes de D. Maingueneau, não é possível tratar do conteúdo de um texto (verbal ou não verbal, já que a prática discursiva é compreendida como intersemiótica) sem se considerar os modos de dizer ou vice-versa, visto que o ethos do texto (seu tom) se constitui na interseção desses aspectos. Para o autor, "o que é dito e o tom com que é dito são igualmente importantes e inseparáveis" (1997: 46), não havendo hierarquia entre o "conteúdo" e o modo de dizer, uma vez que a eficácia de um discurso (mensurada por sua capacidade de suscitar a crença) está diretamente ligada ao ethos que ele constrói e, ao mesmo tempo, sustenta. Para Maingueneau:

o texto escrito possui, mesmo quando o denega, um tom que dá autoridade ao que é dito. Esse tom permite ao leitor construir uma representação do corpo do enunciador (e não, evidentemente, do corpo do autor efetivo). A leitura faz, então, emergir uma instância subjetiva que desempenha o papel de fiador do que é dito (Maingueneau 2000: 98).

Ainda segundo o autor, "a eficácia do ethos decorre do fato de que envolve de alguma forma a enunciação, sem ser explicitado no enunciado" (2005b: 70). Essa não necessidade de explicitação (no enunciado) 
decorre do fato de que as situações de enunciação se constituem no quadro de uma "cena de enunciação", que não se confunde com um simples quadro empírico, mas "se constrói como cenografia por meio da enunciação". Segundo essa concepção, "o discurso implica um enunciador, um co-enunciador, um lugar e um momento da enunciação que valida a própria instância que permite sua existência", sendo que a "cenografia é ao mesmo tempo dada e construída" (2006: 47). No caso da obra Mona Lisa, por exemplo, ela se "diz" misteriosa e profunda ao apresentar, em sua materialidade, os traços de mistério e profundez, especialmente através de seu sorriso e do olhar. É claro que o grau de sofisticação de Da Vinci, próprio de um grande artista, ultrapassa a simples retomada de uma caracterização de mistério e, de certo modo, institui, a partir de sua criação, uma representação de mistério - sua obra, ao mesmo tempo, retoma e funda (artisticamente) uma noção de mistério, evidenciando um paradoxo que é constitutivo da enunciação, porém aqui elevado a um grau maior de sutileza.

Em nossa análise, a cena englobante, que corresponde ao tipo de discurso e a ele confere seu estatuto pragmático, é o discurso da arte. A cena genérica, que é a "do contrato associado a um gênero, a uma 'instituição discursiva'”, é caracterizada por um tipo específico de obra de arte, a pintura, sendo que cada uma dessas obras específicas (em nosso exemplo, Mona Lisa), constitui uma cenografia distinta. Conforme ressaltamos, com base em Maingueneau, a cenografia não deve ser interpretada como uma simples cena ou um quadro estável. "Na verdade é preciso concebê-la ao mesmo tempo como quadro e como processo", ou seja, "o discurso implica uma certa situação de enunciação, um ethos e um 'código linguageiro' através dos quais se configura um mundo que, em retorno, os valida por seu próprio desenvolvimento" (Maingueneau 2006: 47).

O leitor reconstrói a cenografia de um discurso com o auxílio de indícios diversificados, cuja descoberta se apoia no conhecimento do gênero de discurso, na consideração dos níveis da língua, do ritmo, etc. ou mesmo em conteúdos explícitos. Em uma cenografia, como em qualquer situação de comunicação, a figura do enunciador, o fiador, e a figura correlativa do co-enunciador são associadas a uma cronografia (um momento) e a uma topografia (um lugar) das quais supostamente o discurso surge. (Maingueneau 2005b: p. 77) 
Entende-se, então, que o conceito de ethos está diretamente ligado à cena de enunciação, que põe em foco certa(s) cenografia(s), vinculadas, por sua vez, a estereótipos. Assim, nossas análises descreverão cenografias em torno do quadro original de Da Vinci, bem como em algumas releituras suscitadas por esta obra, que comportam a construção de um ethos específico, entre outras coisas, amparado em situações constituídas via estereótipos sociais existentes, memória discursiva e interdiscurso: "a cenografia é, assim, ao mesmo tempo, aquela de onde o discurso vem e aquela que ele engendra; ela legitima um enunciado que, por sua vez, deve legitimá-la" (Maingueneau 2005b: 77).

A noção de ethos - crucial para a (re)constituição da cenografia da qual participa e deriva - está, portanto, diretamente ligada à enunciação, "não a um saber extradiscursivo sobre o enunciador" (Maingueneau 2005b: 70). E "longe de situar-se na nascente do texto [...], o tom específico que torna possível a vocalidade constitui para nós uma dimensão que faz parte da identidade de um posicionamento discursivo" (Maingueneau 2005b: 73). O ethos é, portanto, mais do que um meio de persuasão, sendo "parte constitutiva da cena de enunciação, com o mesmo estatuto que o vocabulário ou os modos de difusão que o enunciado implica por seu modo de existência" (Maingueneau 2005b: 75).

Esses conceitos - ethos discursivo, cenografia, cenas da enunciação, entendidos em sua reciprocidade - subsidiam, de forma imbrincada, as descrições e análises sobre a obra de Da Vinci e algumas de suas diversas releituras, a fim de se procurar entender os sentidos em torno desta famosa obra de arte, a Mona Lisa.

É importante, ainda, uma ressalva sobre a noção de metáfora, à qual recorreremos: esta deve ser entendida dentro do quadro teóricometodológico da Análise do Discurso de linha francesa, segundo o qual não existe uma dicotomia entre sentido literal e sentido(s) metafórico(s). Uma vez que os sentidos se constituem dentro de um certo quadro de enunciação, vinculado a posicionamentos histórico-ideológicos, as metáforas são constitutivas do sentido. Por outro lado, a rigor, todo sentido é necessariamente metafórico. Desse modo, a metáfora deve aqui ser entendida como parte integrante do ethos discursivo. Em contrapartida, como veremos, o "sorriso de Mona Lisa" torna-se "metáfora", em 
sentido corrente de figura de linguagem, para a noção de "mistério", o que deve ser considerado em nossa leitura, desde que sinalizado o necessário deslocamento teórico da noção de metáfora para a teoria discursiva. Ou seja, a metáfora aqui é, em termos teóricos, compreendida discursivamente, porém a noção literária de "metáfora" enquanto figura de linguagem interfere (discursivamente) nos efeitos de sentidos do quadro Mona Lisa. Sinalizado esse deslocamento teórico, pode-se dizer que, em nossa análise, as noções discursiva e literária de metáfora são complementares, mas não se opõem a um "sentido literal".

\section{Sorriso de Mona Lisa, uma metáfora, um ethos}

O filme O sorriso de Mona Lisa (Mona Lisa Smile, 2002) traz Julia Roberts como uma professora de História da Arte, Katharine Watson, que começa a dar aulas em uma escola conservadora. Há todo um conflito de visões de mundo, já que as alunas estão inseridas em um universo caracterizado por discursos segundo os quais o papel das mulheres é cuidar de um lar, enquanto a professora propõe uma visão em que as mulheres têm escolhas, que podem ser profissionais etc., posição inovadora para a época em que se passa o filme, a década de 1950. No decorrer da trama, percebe-se que não se trata exatamente de uma dualidade, de dois discursos opostos, mas de posicionamentos que podem conviver e relacionar-se entre si. O desfecho é, de certa forma, desestabilizador, já que uma aluna que havia sido aprovada para a Universidade (Joan Brandwyn, interpretada por Julia Stiles) opta pelo casamento, o que contradiria a ideologia defendida pela professora. No entanto, é possível considerar que, ao aproximar-se dos discursos conflitantes, a personagem aluna teve a possibilidade da escolha: o casamento pode ter sido uma opção, não a única que tinha. De forma muito resumida, pode-se dizer que o filme, mais do que trazer à tona discursos opostos, mostra que eles convivem entre si, ora de forma complementar, ora conflituosa. Assim, não há um posicionamento "correto" que corresponda à certeza da felicidade, ao sorriso genuíno. Portanto, os sorrisos são sempre enigmáticos, como o de Mona Lisa.

Este filme é um exemplo da "metáfora" que ganhou vida própria, a do sorriso de Mona Lisa. Figurativamente, pode-se dizer que o sorriso de Mona Lisa é uma metonímia (um aspecto recortado de um todo 
que serve para identificar esse todo) que extrapola "metaforicamente" seu contexto original, materializando um sentido para "mistério": por similaridade (construída discursivamente), o sorriso de Mona Lisa pode servir, em sentido figurado, para caracterizar algo supostamente misterioso.

Não se pode afirmar, a rigor, que o sorriso misterioso proposto por Da Vinci seja de felicidade, tristeza disfarçada, ironia, desprezo, indignação, sedução ou bom humor, embora qualquer uma dessas emoções possa estar presente. Como preza a Arte, os sentidos são múltiplos em torno do efeito de sentido do mistério. Das diversas paródias de Mona Lisa, algumas focalizam menos o sorriso. Mesmo assim, só pelo fato de atualizar a personagem em uma outra cena de enunciação, é evocada a questão do mistério em torno de seu sorriso, já que é este um traço essencial de seu ethos.

Muito já se discorreu a respeito do sorriso de Mona Lisa. Diz-se que se trata de um sorriso recatado, comportamento valorizado na época em relação às mulheres. Uma história, não se sabe se verdadeira, contada pelo biógrafo Giorgio Vasari - retomada pela revista Veja (Teixeira 2004: 98) -, prega que haveria músicos no salão em que Leonardo pintava, para que a modelo sorrisse. Fantasiosa ou não, a história inspirou um quadro de Cesare Maccari (1863). Embora tenha se cogitado até que a mulher retratada pudesse ter sido uma prostituta (já que não era comum que as mães de família usassem os cabelos soltos), dados históricos permitem considerar que se trata realmente de uma aristocrata.

Segundo reportagem da revista Veja (Ribeiro 2006), pesquisas do Centro de Pesquisa e Restauração dos Museus da França (C2RMF) e do Conselho Nacional de Pesquisas do Canadá (NRC) constataram que "a serenidade da Gioconda traduziria (...) o sentimento de plenitude maternal”, já que havia acabado de dar à luz o seu segundo filho. Técnicas de análise com luz rasante, raios X, infravermelhos e ultravioleta permitiram a apreensão de detalhes como o fato de que a retratada, Lisa Gherardini, utilizava um véu característico das mulheres grávidas ou que acabaram de dar à luz, levando à conclusão de que o retrato teria sido feito em comemoração ao nascimento do filho e permitindo arriscar a precisão da data de sua criação: 1503. 
O título e olho (subtítulo) da matéria de Veja, "Um mistério a menos - Uma formidável bateria de exames revela por que a Mona Lisa sorria: de felicidade materna", procura construir textualmente a objetividade, a verdade jornalística, por meio de expressões como "mistério a menos"; "por que (...) sorria". No entanto, o sorriso desenhado por Da Vinci permanece com seus múltiplos (misteriosos) sentidos, tal qual a ironia:

A ironia é o discurso se assumindo como máscara, como sorriso postiço que nos impele à decifração de seu segredo e já se diverte com o nosso fracasso anunciado e antecipado. Mona Lisa rindo zombeteira dos entendidos de arte que disparam assertivas sobre seu mistério ao desfilarem à sua frente no Louvre. Da Vinci gozador, se divertindo com o fato de que o segredo de sua Gioconda é que não há segredo, há fabricações, criações, feitas por sua mão, cujo sentido definitivo nem ele mesmo conhece. O sujeito do discurso irônico sabe que o que diz não é propriamente o que a coisa é e sabe que a coisa nunca é aquilo de que dela se diz. (Albuquerque Jr. 2006: 100)

Ora, se as análises técnicas esclarecem detalhes técnicos e de costumes de época, não esgotam os mistérios do sorriso de Mona Lisa nem seus múltiplos sentidos. Como se disse, ao retratar a Mona Lisa, Leonardo Da Vinci registrou muito mais da humanidade do que de uma única mulher, daí a força e permanência de circulação desses discursos. Independentemente de ter retratado uma possível serenidade maternal, conforme os indícios históricos acima descritos, o sorriso de Mona Lisa ganhou o sentido de metáfora para mistério, para o desconhecido ou, dito em outras palavras, para a conjunção de múltiplos sentidos possíveis em torno de discursos que circulam. Seu(s) sentido(s), portanto, extrapola $(\mathrm{m})$ qualquer tentativa de esclarecimento histórico, uma vez que as condições de produção são parte integrante do sentido, mas não definem $o$ sentido por excelência.

\section{Aforização de um sorriso}

O sorriso de Mona Lisa, característico da intensidade da expressão da pintura, é um traço marcante da autoria de Leonardo Da Vinci. Simultaneamente, é das expressões mais destacadas quando se pretende 
definir o ethos de Mona Lisa - ethos característico de um estado da humanidade, ou do próprio enigma de ser humano, que se enuncia a partir de certa cenografia, incorporado em uma certa personagem.

Sabemos que, "na maior parte das vezes, o enunciado sofre uma alteração quando é destacado" (Maingueneau 2010: 13). Com o sorriso de Mona Lisa destacado e "sobreasseverado" pelo autor original, Da Vinci, abre-se a possibilidade de "uma saída do texto, uma destextualização” (Maingueneau 2010: 11).

A expressão "sorriso de Mona Lisa", quando destacada, ganha características de um enunciado aforizante.

$\mathrm{Na}$ enunciação aforizante (...) não há posições correlativas, mas uma instância que fala a uma espécie de 'auditório universal' (Perelman), que não se reduz a um destinatário localmente especificado: a aforização institui uma cena de fala onde não há interação entre dois protagonistas colocados no mesmo plano. O locutor não é apreendido por tais ou tais facetas, mas em sua plenitude imaginária: não há ruptura entre uma instância fora da enunciação e uma instância que é um papel discursivo. É o próprio indivíduo que se exprime, além/aquém de todo papel, 'ele mesmo', de alguma forma. Fundamentalmente monologal, a aforização tem como efeito centrar a enunciação no locutor. (Maingueneau 2010: 13)

Assim, "na aforização, o enunciado pretende exprimir o pensamento de seu locutor, aquém de qualquer jogo de linguagem: nem resposta, nem argumentação, nem narração, mas pensamento, dito, tese, proposição, afirmação soberana...” (Maingueneau 2010: 14). O enunciado aforizado "tende à homogeneidade", além de, cenograficamente, pretender se constituir como "uma forma de dizer puro, quase próxima de uma consciência” (Maingueneau 2010: 14). Contesta-se, assim, "a inevitável espacialização da memória discursiva que cada texto constrói”. É por isso que se pode dizer que "a aforização pretende escapar ao fluxo de comunicação, ser pura fala" (Maingueneau 2010: 14).

Se, ainda como diz Maingueneau, "a enunciação aforizante implica a utopia de uma fala viva sempre disponível” (Maingueneau 2010: 14), pode-se assim compreender o sorriso de Mona Lisa: utopia de um estado sempre vivo e disponível para evocar o mistério dos inexplicáveis 
sentimentos humanos, a partir da retomada de um traço significativo (via destacamento) da cenografia proposta por Da Vinci. Atualiza-se o sorriso memorável que, ao ser enunciado, constrói-se como "repetição constitutiva".

\section{Circulação de sentidos: um ethos, várias cenografias e estereótipos}

O famoso quadro de Da Vinci suscitou reproduções, releituras, paródias, sátiras, homenagens não menos famosas. Olhar para algumas delas permite uma abordagem da circulação de sentidos que compõem um ethos discursivo em torno desta consagrada obra de arte.

Basta fazer uma busca no google ou folhear livros de arte para se deparar com as mais diversas representações de Mona Lisa, entre as quais estão La Joconde, XVII siécle, de Valencinnes, musée des Beaux-Arts; Portrait de Mona Lisa, de Claude-Ferdinand Gaillard, musée du Louvre (1886-1887). O século XX, sobretudo, foi fértil em releituras de Mona Lisa, entre as quais está a também famosa Mona Lisa de bigode, L.H.O.O.Q., de Marcel Duchamp (1919), que imita o quadro original com o detalhe humorístico do bigode e cavanhaque, como que pintados à caneta esferográfica, marcando um contraponto entre o clássico (a pintura original) e o moderno (a caneta). Outra bem conhecida é Mona Tsé-Tung, Roman Cieslewicz, musée d'art contemporain (1976). Há ainda a obra colorida de Andy Wahol (1963), intitulada Thirty are Better Than One, em que várias Monas Lisas são representadas em cores diferentes, numa alusão crítica à cultura de massa e ao consumismo; além de uma versão de Mona Lisa gorda, a Mona Lisa, de Fernando Botero (1978).

A releitura mais inusitada em relação à obra original talvez seja a La Joconde est dans les escaliers, de Robert Filiou (1968); nela, em lugar do famoso rosto de Gioconda, encontram-se um balde vermelho, um pano de chão e uma vassoura com o cartaz afixado: "La Joconde est dans les escaliers" - seria uma nova forma de representar a dona de casa, segundo certos estereótipos sobre o papel da mulher como cuidadora do lar? 
Além dessas releituras "oficiais", circulam na internet imagens de Mona Lisa, sem autoria definida. Como os provérbios, muitas dessas figuras têm sua autoria original "perdida" no tempo e no espaço, o que não elimina a possibilidade de poder ser comprovada e reivindicada. Trata-se da dificuldade de se lidar com o estatuto da autoria nos tempos de internet, conforme discutimos em Moraes (2012) com respaldo em Maingueneau (2010). O funcionamento da autoria é, nesses casos, ainda mais complexo por se tratar de releituras sobre outra autoria original. Encontram-se exemplos em que:

- Mona Lisa é representada com uma mão em frente a seu rosto, como quem diz "Chega" ou "Cansei” (possível brincadeira com o fato de a personagem estar cansada de tanta exposição);

- Mona Lisa tem cabelos curtos e é acompanhada do enunciado verbal "Cansei" (dos cabelos compridos?);

- Mona Lisa usa chapéu de bruxa;

- Mona Lisa é vestida de soldado, com o mote "Guerra ao Terror";

- Mona Lisa faz pose para a foto, de calça jeans, blusa curta e barriga à mostra, postura sensual;

- Mona Lisa tem decote ousado e sensual, parte dos seios à mostra e boca carnuda;

- Mona Lisa está de óculos escuros;

- Mona Lisa toca violão etc.

Circula também, especialmente pelo facebook, uma brincadeira com o jogo linguístico "Mona Lisa e Mona Crespa", em que, ao lado da representação tradicional, tem-se outra com o cabelo crespo. Estas duas representações (crespa e lisa) circularam em conjunto, com a assinatura do site www.fabricadequadrinhos.com.br, acompanhadas dos seguintes dizeres:

“Chapinhas São Leonardo. Há 500 anos fazendo as cabeças das mulheres. Antes: Mona Crespa. Depois: Mona Lisa." 
Certamente, a marca "São Leonardo" para o aparelho de chapinha é uma brincadeira com o nome do pintor, Leonardo Da Vinci. Há aí uma atualização da pintura do século XVI com o discurso predominante do século XXI sobre a beleza feminina, que convencionou atribuir o caráter de belo/correto ao cabelo liso, comportado, enquanto o cabelo crespo tem valor cultural negativo, aspecto também apontado em análise de anúncio publicitário por Silveira (2010).

Entre artistas contemporâneos brasileiros, temos a "Mônica Lisa", de Maurício de Souza, que representa sua principal personagem infantil, a Mônica, na cenografia da Mona Lisa original. Também uma representação tipicamente colorida de Romero Britto, a "Mona Cat", em que uma Mona Lisa com traços geométricos é caracterizada com rosto de gato.

Sobre Mônica Lisa, Silveira a descreve ao estudar a sua intertextualização numa campanha publicitária da Brasil Telecom:

O fundo mais ou menos é mantido, havendo alteração na cor; a cabeça é modificada pela figura da Mônica, mas de forma a se manter, nela, um olhar enigmático entre o triste e o sombrio, apresentando similitude com o quadro original. Entretanto, há o cancelamento do nariz e a modificação do sorriso, pelo traço labial e introdução de dois grandes dentes. A figura da Mônica é de cabelos curtos, ao passo que a da Mona Lisa é de cabelos longos. A posição das mãos foi mantida, mas há ligeira modificação na posição do decote, do vestido e do xale e nas cores, de modo a manter uma similitude com o estilo da Mônica. A criança brasileira foi representada na imagem com o valor culturalmente positivo atribuído à alegria. Dessa forma, na Mônica Lisa, a introdução dos dentes da Mônica ressemantizam a figura original, modificando o traço enigmático em inocência alegre e infantil. (Silveira 2010: 40)

O livro História em Quadrões, que reúne imagens de pinturas de Maurício de Souza baseadas em obras de arte famosas, ao expor a Mônica Lisa (acrílica sobre tela de 1989), apresenta informações sobre o artista Leonardo Da Vinci e, em tom bem-humorado, descreve: “A Mônica caprichou no sorriso para ficar parecida com Lisa de Giocondo, pintada por Leonardo da Vinci” (Souza 2002: 15).

Como ponto comum entre as releituras diversas, há o fato de que a personagem que representa a paródia de Mona Lisa ocupa sempre o 
centro do quadro e demonstra alguma atitude: seja a de sensualidade (decote sensual), a de revolução (soldado) ou de rebeldia em relação às convenções de beleza contemporânea (a Mona Crespa) ou a brincadeira/intertextualidade com outras personagens (como a Mônica Lisa, de Maurício de Souza). Num certo sentido, mantém-se o ethos de Mona Lisa como figura enigmática, central, única e, ao mesmo tempo, representativa de toda uma humanidade. No entanto, muitas vezes, o que é peculiar de Leonardo Da Vinci, marca primorosa de sua autoria, perde-se nas releituras; a atenção já não se concentra tanto no enigma da expressão, especialmente do sorriso, mas no reforço de outros estereótipos: a sensualidade, a austeridade da guerra, a remissão ao imaginário de beleza (Mona Lisa versus Mona Crespa) ou mesmo a expressão das cores e das formas (como na obra de Romero Britto).

A escolha de uma cenografia diversa, ainda, multiplica as possibilidades de caracterizações de Mona Lisa, a um só tempo tornando-a mais real (inserida em um contexto - o da Guerra, por exemplo - e, portanto, em certo sentido, desprovida de sua universalidade) e, paradoxalmente, mais ficcional.

Somem-se ainda as representações desenvolvidas por crianças em atividades escolares, como a Emo-Lisa, de Emanuel Souza Barreira, então com 10 anos de idade (2008). Nota-se que o estudante une o aprendizado sobre a obra de arte Mona Lisa ao seu repertório sobre o universo "emo"1, cujo estereótipo é caracterizado por um estilo comum entre alguns músicos e bandas, especialmente conhecidos entre crianças e jovens. Há um jogo linguístico entre "Mona" e "Emo", com substituição dos termos e manutenção do nome "Lisa".

1. "Emo vem do termo emocional hardcore, um estilo de música nos anos 80 no punk rock. Mas é também utilizada como uma cultura alternativa, um estilo de vida, que se propagou no Brasil e pelo mundo. Muitos jovens se identificam com a ideologia emo, mas o que mais chama atenção é a maneira de se vestir. As roupas dos emos geralmente são pretas, mas podem até utilizar uma peça ou outra de cor clara, cabelos bem tingidos de negro e franjas longas caídas no rosto (...)”. FONTE: <http://www.significados.com. br/emo/> Acesso em outubro/2012. 


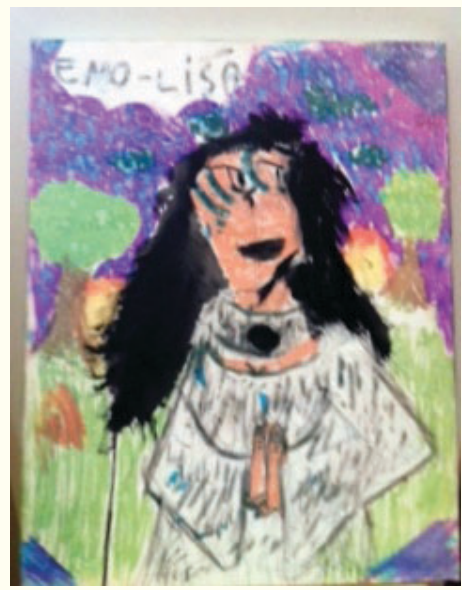

Figura 2: Emo-Lisa. (Emanuel Souza Barreira. Fonte: Arquivo Pessoal)

Emo-Lisa é alegre, tem um sorriso aberto, cabelos soltos ao vento, o que remete ao cabelo do roqueiro, estilo que carrega alguma similitude com o emo. Embora possa ser atribuído ao estilo emo um estado de melancolia, solidão, este pode ser caracterizado como introspecção ou reflexão, o que aparece na postura contemplativa desta Emo-Lisa. A paisagem tem cores alegres, predominando o verde ao invés dos tons escuros do original de Da Vinci, assim como é alegre o sorriso de Emo-Lisa. No conjunto, a pintura não deixa de trazer cores mais ligadas ao universo musical emo, como o roxo (no céu), o preto (nos cabelos), o branco (na roupa), o que pode ser observado na caracterização de músicos desse estilo, acompanhada de uma moda emo, que fez sucesso especialmente na época de produção desta pintura. A remissão à Mona Lisa original dialogou com o repertório sobre emo, conhecido da criança-autora, e, sobretudo, predominou a alegria de um universo infantil.

Todas essas representações atualizam constantemente a tradicional figura de Mona Lisa, partindo de traços comuns, porém enfatizando em diferentes graus uma das principais marcas de autoria de Da Vinci - o sorriso enigmático - e acentuando outros traços e estereótipos. Mesmo quando não enfatizado, a remissão ao sorriso de Mona Lisa está presente, por interdiscursividade, nas releituras. 


\section{Mona Lisa: texto e discurso}

Pêcheux ([1969]1990) observa que, apesar de o corte saussureano ter mudado a Linguística de terreno, certas perguntas não deixaram de ser feitas, a exemplo de o que um texto significa. Como consequência de um viés discursivo, o autor deixa claro que "é impossível analisar um discurso como um texto, isto é, como uma sequência linguística fechada sobre si mesma, mas é necessário referi-lo ao conjunto de discursos possíveis a partir de um estado definido das condições de produção" (Pêcheux [1969]1990: 79, itálico no original).

Podemos, então, entender que, mais do que uma intertextualidade, as diversas representações de Mona Lisa fazem circular uma interdiscursividade. Certos discursos, como o sobre o aspecto enigmático da expressão humana, materializam-se nessa dispersão de textos que são as releituras do quadro de Da Vinci, as quais vão das obras de pintores famosos, clássicos e modernos, às atividades escolares das crianças.

Possenti (2010) assinala a necessidade de se dar conta de que a própria textualidade é gerida por categorias discursivas. Assim, é importante observar que não só o conteúdo a respeito da expressão enigmática (para focarmos nesse exemplo) circula, mas um certo ethos, representado em um certo enquadramento: a centralização da personagem em primeiro plano, sua postura, seu olhar, seu sorriso, cujo grau de fidelidade em relação ao original de Da Vinci varia conforme a proposta do "novo autor". Como diz Possenti (2010: 77), "a mesma semântica que determina o que pode e deve ser dito seleciona, de alguma forma, em que textos isso se dirá e, na mesma medida, como isso se dirá, pelo menos, qual é o tom requerido", já que a "doutrina" é em realidade "inseparável de uma discursividade, de um modo de enunciação, de um processo de "incorporação"” (Possenti 2010: 78).

A organização dos conteúdos de um discurso em torno da obra Mona Lisa não é dissociada de sua cena de enunciação, no sentido de Maingueneau, assim como as diversas releituras se pautam nessa cena de enunciação, podendo acrescentar nuances que fazem circular estereótipos diversos, apelando sempre para "cenas validadas". Assim, o "discurso deve ser concebido como uma prática e (...), como tal, suas dimensões são mais amplas do que o que 'significam' os textos. (...) essas outras dimensões, inclusive o tom do enunciador, podem 
explicar-se pelo recurso a uma semântica discursiva" (Possenti 2010: 80), conforme proposto por Maingueneau (2005a).

A cada releitura, pode haver variação de estilo, concebido como "um modo de organizar uma sequência (...), tendo como fundamental a relação entre essa organização e determinado efeito de sentido, sem compromissos com psicologismos e com concepções simplórias de língua e de linguagem" (Possenti 2010: 93), com o cuidado de "não desprezar o próprio processo de inscrição do sujeito, naquilo que ele tem efetivamente de processo" (Possenti 2010: 96).

\section{Considerações finais}

A Mona Lisa, ou Gioconda, é o maior ícone renascentista do século XVI e talvez o mais popular em nossos tempos, o que teve influência de toda uma conjuntura histórica, conforme procuramos descrever. Até os dias de hoje, nunca deixou de suscitar perguntas a respeito de sua expressão enigmática, especialmente em torno de seu sorriso.

O fato de ter extrapolado os cânones da chamada alta cultura e se popularizado fez com que a obra se tornasse fonte das mais diversas retomadas e destacamentos, multiplicando seus efeitos de sentido, sem deixar de perpetuar certos traços de seu ethos, cujo mistério (materializado pelo sorriso extraído de sua cenografia) é uma das principais marcas.

A obra original tem a autoria de Da Vinci, enquanto as releituras carregam traços dessa autoria original e traços de singularidade, que pode ser entendida como "tomada de posição" em relação ao estereótipo que "pretende" fazer circular ou enfatizar. Como reitera Possenti, "um texto só pode ser avaliado em termos discursivos", sendo que a "questão da qualidade do texto passa necessariamente pela questão da subjetividade e de sua consequente inserção num quadro histórico - ou seja, num discurso - que lhe dê sentido" (Possenti 2010: 106). É assim que se pode pensar na autoria das diversas releituras de Mona Lisa.

Recebido em: maio de 2013 Aprovado em: setembro de 2013 


\section{Referências bibliográficas}

Albuquerque Jr., Durval Muniz de. 2006. Michel Foucault e a Mona Lisa ou Como escrever a história com um sorriso nos lábios. In: RAGO, M. e VEIGA-NETO, A. (Orgs.) Figuras de Foucault. Belo Horizonte: Editora Autêntica. pp. 97-107.

DouAR, Fabrice. 2005. La Joconde - un portrait modéle. In: La Joconde. Connaissance des Arts. Musee du Louvre Éditions.

Loyrette, Henri. 2005. Préface. In: La Joconde. Connaissance des Arts. Musee du Louvre Éditions.

Maingueneau, Dominique. 1997. Novas Tendências em Análise do Discurso. 3. ed. Campinas (SP): Pontes/ Editora da Unicamp. Edição original: 1987.

. 2000. Análise de textos de comunicação. São Paulo, Editora Cortez.

.2005a. Gêneses do Discurso. Tradução de Sírio Possenti. Curitiba (PR): Criar Edições.

. 2005b. Ethos, cenografia, incorporação, in: AMOSSY, R. (org.) Imagens de si no discurso - a construção do Ethos. São Paulo, Editora Contexto, pp. 69-92, 2005.

. 2006. Cenas da Enunciação. Curitiba (PR): Criar Edições.

2010. Doze conceitos em Análise do Discurso. São Paulo (SP): Editora Parábola.

Moraes, Érika de. 2012. Mídias sociais, identidade e autoria. Revista Estudos Linguísticos, São Paulo, v. 41 (3), p. 936-947.

PÊcheux, Michel. 1990. Análise automática do Discurso. In: GADET, F. \& HAK, T. (Org.) Por uma análise automática do discurso: uma introdução à obra de Michel Pêcheux. Tradução de Eni P. Orlandi. Campinas (SP): Editora da Unicamp. Edição original: 1969.

Possenti, Sírio. 2010. Questões para Analistas do Discurso. São Paulo: Parábola.

Ribeiro, Antonio. 2006. Um mistério a menos - Uma formidável bateria de exames revela por que a Mona Lisa sorria: de felicidade materna. Revista VEJA, Editora Abril, Edição 1976, de 4 de outubro de 2006. pp. 134-5.

SAssoon, Donald. 2004. Mona Lisa - A história da pintura mais famosa do mundo. São Paulo: Editora Record.

Silveira, Regina Célia Pagliuchi da. 2010. Cultura e mídia em textos multimodais. In: VIEIRA, A. A., BENTO, A. L. e ORMUNDO, J. S. Discursos nas Práticas Sociais - perspectivas em multimodalidade e em gramática sistêmico-funcional. São Paulo: Editora Annablume. pp. 36-49. 
SouzA, Maurício de. 2002. História em Quadrões - Pinturas de Maurício de Souza. Editora Globo/Maurício de Souza Editora.

TeixeIRA, Jerônimo. 2004. A modernidade de Da Vinci. Revista Veja, Editora Abril, Edição 1877, de 27 de outubro de 2004. P. 95-101.

VAux, Carra de. 1943. Leonardo da Vinci. São Paulo: Edições Cultura. Série biográfica de Cultura "Vidas Luminosas". Tradução de Heitor Ferreira Lima. 